\title{
PRUDÊNCIA, JUSTIÇA E HUMILDADE: ELEMENTOS MARCANTES NO MODELO DE MONARCA PRESENTE NAS OBRAS DEDICADAS AO REI SUEVO
}

\author{
Leila Rodrigues Roedel \\ Dept ${ }^{o}$ de História do Instituto de Filosofia e Ciências Sociais - UFRJ
}

\begin{abstract}
RESUMO: O objeto das nossas reflexões, no presente artigo, insere-se nas relações estabelecidas entre a Monarquia e a Igreja no Reino Suevo. Nesse reino, organizado na Península Ibérica, em meados do século VI, a aliança entre as duas instituições mencionadas, proporcionou um ambiente favorável à crescente atuação eclesiástica no âmbito político. A culminância desse processo verificar-se-á na formulação de um modelo ideal de conduta para o monarca no qual são destacados, entre outros elementos, a prudência, a justiça e a humildade. Assim, buscamos aqui uma análise que possa revelar os contornos assumidos por cada um desses elementos no modelo de comportamento idealizado para o monarca, bem como os mais relevantes pressupostos que nortearam tal construção.

ABSTRACT: The main focus of this paper is on the relationships established between Monarchy and Church in the Suevian Kingdom. By the mid-6th century, the alliance between these institutions in this kingdom, organized in the Iberian Peninsula, had created an environment which was increasingly favorable to the political action of the Church's members. The process culminated in the design of an ideal model for the king's conduct whose key elements were prudence, justice and humility. Given this framework, the main effort of this paper is to undertake an analysis which will help to reveal the roles played by each of those elements in the ideal model proposed for the monarch's conduct as well as the underlying assumptions which presided at over this construction.
\end{abstract}

PALAVRAS-CHAVE: Suevos, cristianização, monarquia, política, Martinho de Braga.

KEYWORDS: Sueves, christianization, monarchy, politics, Martin of Braga.

Nas últimas décadas, o estudo da História política tem se renovado e ampliado consideravelmente. Esse revigoramento tem evidenciado que a preocupação com dados políticos isolados, tais como os atos dos reis, as batalhas e a cronologia, retrata apenas uma visão tradicional, não se identificando mais com o que hoje entendemos por História política. Esta, a partir de uma perspectiva diversa daquela que a caracte- 
rizara até então, incorporou novos métodos, abordagens e problemas que, inegavelmente, tem possibilitado sua reabilitação junto aos historiadores.

O objeto das nossas reflexões nesse artigo, inserese, de uma maneira geral, nas relações estabelecidas entre a Monarquia e a Igreja no Reino Suevo. Tal objeto pode, portanto, ser incluído no âmbito político, sim. Há que se conceber, contudo, este espaço como algo muito mais amplo do que aquele criticado por Jacques Julliard (1976, p. 180) que, entre outras manifestações, é elitista, narrativo e biográfico. Destaquemos, pois, que nossa opção pela História política vincula-se à importância que pode assumir, nesse campo, a ideologia. Em tal sentido, interessam-nos, particularmente, as elaborações teóricas associadas ao poder real realizadas pelos eclesiásticos que viveram no reino suevo, organizado na Península Ibérica, em meados do século VI.

Nesse reino, a aliança entre a Igreja e a Monarquia, inaugurada com a conversão do rei suevo ao cristianismo (FERREIRO, 1981, p. 14-15), tornou possível a existência de um ambiente no qual a ação eclesiástica pôde se manifestar na constituição de mecanismos de influência junto às autoridades políticas. Ao longo do processo de reorganização e fortalecimento da Igreja na região, tais mecanismos puderam ser desenvolvidos e aperfeiçoados. Dessa forma, os religiosos passaram a desfrutar de um espaço de atuação crescente favorecido pela possibilidade de orientação espiritual; participação na formação intelectual e aconselhamento pessoal das autoridades políticas do reino. A culminância desse processo verificar-se-a na formulação de um modelo ideal de conduta para o monarca.

Acreditamos que a obra do bispo de Braga, Martinho, composta de variados escritos (MARTINI EPISCOPI BRACARENSIS, 1950) ${ }^{1}$, no que concer-

\footnotetext{
${ }^{1} \mathrm{O}$ corpus martiniano é consideravelmente extenso, compreendendo obras de cunho litúrgico, ascético, moral, disciplinar e doutrinário
}

ne ao conjunto dedicado ao rei suevo, apresenta em suas linhas e entrelinhas traços que sugerem a formulação de tal modelo de monarca. Isso não se verifica, contudo, de forma sistemática, previamente deliberada ou fechada em um determinado escrito martiniano, mas, em suas múltiplas facetas, encontra-se diluído nas quatro obras oferecidas ao rei Miro².

Diante da impossibilidade de abarcarmos nos limites de um artigo as variadas expressões desse padrão, objetivamos aqui, a partir da reflexão sobre alguns aspectos de duas destas obras, Formula Vitae Honestae e Exhortatio Humilitatis, analisar três dos principais elementos que compõem tal modelo: a prudência, a justiça e a humildade.

\section{Formula Vitae Honestae e Exhortatio Humilitatis ${ }^{3}$}

Formula Vitae Honestae foi produzida no período compreendido entre o começo do governo do rei Miro (570) e a morte de Martinho de Braga (580). Tal obra tem como fio condutor básico a idéia de fornecer indicações a partir das quais se poderia alcançar uma forma de vida correta. Além de sua parte introdutória, constituída pela dedicatória do Bracarense ao rei, e uma breve conclusão que destaca a importância das orientações apresentadas, o referido escrito pode ser dividido em quatro partes, em função dos temas separadamente enfocados: a prudência; a magnanimidade; a continência e a justiça.

${ }^{2}$ Formula Vitae Honestae, Repellenda Jactantia, Item De Superbia e Exhortatio Humilitatis.

${ }^{3}$ Adotamos como abreviaturas das duas obras destacadas, as iniciais das palavras que compõem os títulos: FVH: Formula Vitae Honestae e EH: Exhortatio Humilitatis. Considerando a maior fidelidade e qualidade da tradução realizada pelo último editor das obras de Martinho de Braga, estaremos utilizando para as citações a referida edição (1990) dos escritos do Bracarense. Cf. Bibliografia. 
Diferentemente da quase totalidade da produção martiniana ${ }^{4}$, essa obra não se baseia em uma argumentação exclusivamente cristã. Em outras palavras, se o autor de tal escrito não estivesse claramente identificado, ao analisá-lo, poderíamos afirmar que se trataria de uma obra produzida no âmbito do Estoicismo e não do Cristianismo, embora as duas opções não sejam, como sabemos, necessariamente excludentes (BARNES, 1978; BRUN, 1986; GRIMAL, 1991, $p$. 343-358). Tendo como eixos fundamentais de reflexão a natureza e a razão, Formula Vitae Honestae aborda valores humanos que são caros à religião cristã, sem insistir neste aspecto durante o enfoque da prudência, da continência e da magnanimidade. Ao discorrer, contudo, sobre o último dos quatro elementos destacados, a justiça, observamos uma nova tendência na argumentação martiniana. Tal tendência culminará com a predominância de um tom que sublinha temáticas diretamente vinculadas às Sagradas Escrituras em uma aproximação de cunho eminentemente cristão. O enfoque conferido à justiça antecipa, portanto, o tratamento recebido pela humildade, objeto da outra obra martiniana dedicada ao rei suevo que também será, neste artigo, abordada.

Exhortatio Humilitatis é a parte final de um escrito martiniano dividido em três obras. No conjunto, composto também por Pro Repellenda Jactantia e Item De Superbia, o bispo de Braga realizou considerações sobre a inadequação de um comportamento que se pautasse na jactância, destacou a impropriedade da soberba e forneceu orientações para uma conduta baseada na virtude da humildade, em contraposição aos vícios anteriormente sublinhados.

Embora desprovida de uma dedicatória formal ao rei Miro, Exhortatio Humilitatis, foi-lhe, indubitavelmente, oferecida. Além das várias referências ao mo-

\footnotetext{
${ }^{4}$ Poderíamos destacar como exceções, além da Formula Vitae Honestae, apenas De Ira e um dos seus poemas, In Basilicam.
}

narca que contém (EH., IV, p. 87; IV, VIII, p. 89-90; I, p. 90), os assuntos que trata fazem com freqüência menções ao poder. Esta obra, diferentemente da Formula Vitae Honestae, recebeu em toda a sua extensão um enfoque diverso daquele que poderia associar Martinho ao estoicismo. O bispo bracarense não se afastou das questões morais, todavia imprimiulhes um outro caráter, ou seja, concedeu à humildade um perfil exclusivamente cristão. Esse escrito sugere, pois, um contexto de considerável familiaridade do monarca com temas cristãos, o que certamente se relaciona à possibilidade de que tal obra lhe tenha sido oferecida em data posterior àquela da Formula Vitae Honestae. O referido momento já corresponderia, assim, a uma fase de maior influência dos eclesiásticos junto ao monarca que, a partir da aliança entre a Monarquia e a Igreja, manifestou-se de forma crescente. Nesse sentido, Martinho, em mais de uma oportunidade, sugeriu ao seu destinatário que se recordasse desta ou daquela passagem das Sagradas Escrituras (EH., V. p. 89; III, VIII. p. 90-91).

Antes de nos debruçarmos sobre os três elementos por nós eleitos, dentre aqueles que participam da composição do modelo de monarca idealizado, precisamos realizar algumas breves considerações sobre sua autoria quanto a dois aspectos: primeiro, estando o mencionado modelo presente em obras escritas por Martinho, desejamos destacar que as qualidades literárias do bispo bracarense não são objeto do nosso trabalho. Em outras palavras, ao enfocarmos três dos elementos que compõem o padrão de monarca formulado no Reino Suevo, interessa-nos, preferencialmente, uma análise que possa revelar a importância desses no conjunto modelar; as especificidades que os caracterizam, ou seja, os contornos assumidos por cada um, bem como a relação de tais elementos com as particularidades da conjuntura em que o dito modelo fora apresentado ao rei Miro.

Segundo, embora reconheçamos, como também o fizeram os contemporâneos de Martinho (PAS- 
CHASIUS, 1879, p. 1026; FORTUNATUS, V., 1862, v. 88, p. 180; GREGOIRE DE TOURS, 1996, p. 300; ISIDORO DE SEVILLA, 1975, p. 319, red. larga), que este possuía características que o capacitavam a se tornar o mais destacado representante intelectual e religioso do Reino Suevo, não podemos atribuir-lhe exclusividade na formulação do modelo de monarca em questão. Acreditamos, pois, que tal construção seja resultado de um conjunto de inquietações, interesses e expectativas do episcopado local. Este conjunto fora, portanto, incorporado e apreendido pelo bispo de Braga que, a partir de sua bagagem intelectual e experiência, dera-lhe uma marca pessoal.

\section{Prudência}

Nas obras dedicadas ao monarca, algumas virtudes receberam especial atenção, tendo-lhes sido reservado um espaço destacado. Esse é, por exemplo, o caso da prudência, enfocada na Formula Vitae Honestae.

São muitos os pontos sobre os quais Martinho recomendou a observação da prudência.Um dos focos de atenção na abordagem desta virtude diz respeito à preocupação que o monarca deveria ter quanto à formulação de opinião acerca de algo ou alguém. Segundo Martinho, impunha-se como indispensável um exame atento e repetido, antes de que a última palavra fosse proferida, ou que o juízo final fosse revelado. Evitar-se-iam, assim, atitudes e conclusões precipitadas baseadas apenas na aparência. Martinho reservou para tal questão várias menções, vejamos duas delas (FVH.,2, IV, V,VI,VII, IX. p. 158) ${ }^{5}$ :

Es propio del prudente examinar sus decisiones y no lanzarse a lo falso con fácil credulidad. No definas acerca de lo

\footnotetext{
${ }^{5} \mathrm{Na}$ indicação das referências concernentes ao corpus martiniano, os números arábicos correspondem aos capítulos, quando a obra em questão os possui, e os romanos aos parágrafos
}

dudoso(...)lo mismo que a menudo lo que parece increíble a primera vista luego no resulta falso.( FVH., 2, III. p. 158).

(...) examina y sopesa todo y funda la dignidad de las cosas, no en la opinión de la mayoría, sino en su naturaleza. Porque debes saber que hay cosas que parecen buenas y no lo son, y las hay, por el contrario, que no parecen buenas y lo son (Idem, 2, I. p. 158) (o destaque é nosso).

Em meio a esta última argumentação destacada, Martinho emitiu um curioso parecer sobre o posicionamento da maioria, retomado pelo autor linhas adiante. A definição da verdade e do correto não poderia depender, conforme sua avaliação, da existência de uma maior ou menor quantidade de pessoas opinando a respeito. Assim, mais uma vez, expressouse sobre a questão:

No te impresione la autoridad del que habla, y no te fijes en quién sino en qué dice. Piensa en lo que agrada no a muchos, sino a quiénes (Idem, 2, XV. p. 159) (o destaque é nosso).

Apesar de não termos condições de afirmar que o fato de determinadas questões aparecerem mais de um vez no texto se vinculam, necessariamente, a uma maior preocupação com as mesmas, neste caso, em particular, a possibilidade de que nosso autor desejasse enfatizar seu posicionamento sobre um grupo específico de pessoas atuando junto ao monarca, provavelmente maioria em relação aos eclesiásticos, apresenta-se plenamente viável.

De acordo com a tradição germânica, as assembléias de guerreiros se constituíam em importantes instâncias para a solução de problemas. Após o assentamento e organização do Reino Suevo, estas assembléias não deixaram totalmente de existir, porém com um número mais reduzido de componentes, passaram a ocupar um espaço identificado como Conselhos. A essência de sua razão de ser não fora de todo modificada, ou seja, com base na opinião de seus membros, questões poderiam ser deliberadas a partir da apreciação destes. 
Ao propor que o monarca não se detivesse na opinião da maioria, como elemento definidor de sua conduta, Martinho estava contribuindo para a perda de prestígio dos referidos Conselhos e simultaneamente sugerindo, como critério maior de decisão, a opinião do próprio monarca, desde que pautada em princípios de ordem moral. O respeito a tais princípios impunhase, portanto, como o norteador fundamental a qualquer resolução. A partir da sua consideração, chegarse-ia ao perfeito e ao correto, independentemente da quantidade de pessoas opinando em sentido contrário. Assim, o escrito martiniano recomendava que a autoridade de quem falava, eventualmente um grupo de nobres, membros do Conselho, passasse a se subordinar à decisão do monarca, a despeito do fato de que este fosse minoria.

O cuidado com o efêmero foi também enfatizado pelo bispo de Braga:

No profeses admiración a las cosas transitorias que posees, ni estimes en mucho lo que es caduco, ni guardes como ajeno lo que tienes en tu poder, sino gástalo y úsalo en favor tuyo, como tuyo que es (FVH.,2, II. p. 158).

Se compreendermos las cosas transitorias ${ }^{6}$ como objetos, verificamos que Martinho advertiu para o seu caráter perecível. Assim, embora não se devesse estimá-los exageradamente, segundo o texto, a sua propriedade naturalmente conferia o direito do uso em benefício pessoal. Todavia, se igualmente lembrarmos que a obra de Martinho se dirigia ao governante, las cosas transitorias imediatamente se transformam em referência ao poder. Este não deveria ser valorizado em si próprio. Nesse sentido, Martinho forneceu a Miro elementos que indicavam a responsabilidade do seu cargo e a importância do seu papel. Sua mensagem o alertava para que não se omitisse ou relegasse

6 "Quaecumque autem ex rebus transitoriis possides (...)." (MARTINHO DE BRAGA, 1803. p. 147). a outros as decisões que eram suas, bem como para que fizesse uso do poder de acordo com seus interesses. Evidentemente que aqui, mais uma vez, não se tratava de considerar os interesses de um monarca qualquer, mas de um governante que se pretendia moldar em consonância com os princípios cristãos.

A prudência não poderia também estar associada à intransigência. Se se reconhecia o quão passageiro se apresentava o poder ou volátil tudo que se pudesse adquirir, haveria que se ter também a clareza do momento em que reformular um posicionamento se impunha como a melhor opção. As decisões não deveriam, necessariamente, ser definitivas, já que nada o era, antes sim, apresentarem-se como passíveis de ajustes, caso as circunstâncias assim exigissem.

(...) y según las exigencias de los tiempos y diversidad de asuntos lo requiera, acomódate a las circunstancias, y más bien que mudarte procura adaptarte en algunos momentos, al igual de la mano que es la misma cuando se abre en palma que cuando se cierre en puño (Idem, ibid) (o destaque é nosso).

Os cuidados na emissão de críticas e elogios, bem como no uso em geral da palavra, também teriam que ser considerados pelo monarca prudente, que não deveria cometer excessos. Advertiu Martinho:

No sean tampoco frívolas tus palabras, sino que aconsejen, persuadan o amonesten, o consuelen o manden. Sé parco en alabanzas y mucho más en los vituperios, pues en igual manera que es reprensible la adulación desmesurada, lo es el vituperio excesivo (FVH.,2,X.p.158) (o destaque é nosso).

No exercício das suas atividades no governo, certamente, Miro esteve com freqüência cercado de auxiliares. Em suas funções, estes cometeram inevitavelmente acertos e erros. Segundo a orientação martiniana, apenas comedidamente caberia ao monarca se manifestar a respeito. As suas atenções deveriam ocupar um papel mais nobre, aquele próprio do monarca sábio que preferencialmente aconselha, orienta, 
consola e manda. Martinho insistiu nessa idéia em outra menção:

Acelera lo lento, dá solución a lo dudoso, ablanda lo duro, allana lo difícil (FVH.,2, XIV. p. 158).

Ao cumprir eficazmente estas funções, Miro estaria fornecendo os instrumentos a partir dos quais as atitudes dos seus subordinados seriam previsíveis. Dessa forma, não precisaria recriminar, visto que as circunstâncias não demandariam tal postura; nem teria que se desmanchar em elogios frente a procedimentos já esperados.

Um outro aspecto precisa ainda ser observado na continuidade da argumentação martiniana que antecede a última citação:

Ambas cosas (elogios e críticas) dan lugar a sospecha, la una por lo que tiene de lisonja, la otra por su malignidad (FVH.,2, XI. p. 158).

Sendo o monarca não apenas o governante que se pretendia moldar, mas igualmente o homem que deveria servir de exemplo para os demais habitantes do reino, suas atitudes teriam que considerar a opinião dos que o cercavam. Logo, não caberia aos seus atos uma função propiciadora de críticas, ao contrário, esses deveriam suscitar depoimentos favoráveis ao seu perfil moral. Nesse sentido, atitudes que evitassem excessos poderiam garantir não apenas uma conduta prudente, mas também um juízo favorável acerca da sua pessoa. Recomendava-se, portanto, o equilíbrio:

Observa la justa medida (...)Porque, si la prudencia excede sus límites, penetrarás en el terreno de la astucia y de la timidez, serás tachado de investigador de secretos y de escudriñador de toda clase de culpas, serás tildado de cobarde, receloso, atento, buscando siempre algo, siempre temiendo algo, siempre dudando sobre algo y despertarás las más sutiles sospechas(...) (FVH., 6, I. p. 162) (o destaque é nosso)
Assim como os elogios e as críticas, também as promessas deveriam ser evitadas.

Promete con reflexión y dá con más amplitud que prometiste (FVH., 6, XI. p. 159).

Ao seguir a orientação anteriormente formulada, o monarca idealizado estaria se resguardando. Em outras palavras, se fosse prudente o bastante para prometer apenas o factível e em poucas circunstâncias, não poderia ser acusado de não honrar a própria palavra, pois apenas em raras ocasiões, ao se deparar com fatores que escapassem ao seu controle, estaria impossibilitado de realizar o prometido. De acordo com a recomendação martiniana, pois, o monarca adequado seria o lembrado por sua bondade, eventualmente inesperada, e não aquele recordado por romper compromissos.

Ainda através da prática da prudência, Miro estaria capacitado a se defrontar com as situações mais inusitadas, sem que as mesmas lhe surpreendessem.

Si deseas ser prudente dirige tu mirada hacia el futuro, y para atento tu ánimo en las cosas que pueden acontecer (FVH., 6,V. p. 158)

A partir do estudo das circunstâncias vividas no passado, bem como da análise do presente, o futuro apresentar-se-ia, ao monarca, como uma possibilidade para o alcance do bom êxito.

Si tu ánimo es prudente, repártelo en tres tiempos: ordena el presente, prevé el futuro, recuerda el pasado. Porque quien no medita acerca del pasado, pierde la vida, y el que no reflexiona de antemano sobre el futuro, incautamente tropieza en todo $(\mathrm{FVH}$. , 6,XII. p. 159).

O escritor insiste mais uma vez no parágrafo seguinte: 
Propón a los ojos de tu alma los bienes y males futuros, los unos para poder sostenerlos, los otros para poder refrenarlos (Idem, 6, XIII. p. 159).

Assim, Miro deveria observar não apenas as condições concretas que o cercavam, mas antecipar, mediante uma ótica mais ampliada, o que ainda não se concretizara. A fragilidade militar do Reino Suevo, por exemplo, evidenciada no século anterior (HYDACE, 1974, p. 155-157), não poderia ser desconsiderada no relacionamento com os visigodos estabelecidos, em meados do século VI, na Península Ibérica. Logo, enfrentamentos, como os do passado, com os atuais vizinhos peninsulares, deveriam ser evitados. Todavia, como o controle pleno do futuro foge à capacidade humana, melhor seria avaliar as medidas possíveis de cautela. Nesse sentido, os vínculos estabelecidos, por Teodomiro, com os francos (ISLA FREZ, Amancio, 1990, p. 25; TORRES LÓPEZ, 1963, p. 40; SOARES,1957, p. 381) e os bizantinos (TORRES RODRIGUEZ, 1958, p. 23-25; THOMPSON, 1971, p. 104; PRIETO PRIETO, 1975, p. 80), encaminhamento digno de um governante prudente, precisariam ser mantidos.

Pensar sobre o futuro exigiria, portanto, um exercício de reflexão, pautado no passado e no presente. Somente a partir de tal esforço uma conduta prudente, frente ao futuro, seria construída. O não reconhecimento desses elementos, ao contrário, tornaria estéril todo o processo. Nesse sentido, lembrou Martinho:

No des cabida a pensamientos inútiles y vanos y semejantes a un sueño, en los cuales si tu alma se entretiene, quedará sumida en tristeza cuando arregles todo: antes por el contrario sea tu pensamiento estable y seguro (... ) (FVH., 2, IX. p. 158) (o destaque é nosso)

A compreensão dos próprios limites, atitude esperada do prudente, evitaria os sonhos, ou desejo do inatingível. Conseqüentemente eliminaria as frustra- ções. Nem mesmo o sucesso deveria servir, lembrou Martinho, para alimentar a ambição desmesurada.

Cuando en la vida te sopla favorable la fortuna, detente y párate como en un terreno resbaladizo, y en vez de dar libre salida a tus ímpetos reflexiona sobre adónde y hasta dónde has de llegar (Idem, 2, XVII. p. 159).

Assim, Martinho recordava a Miro, por exemplo, de que o fato de seu pai ter usufruído de um momento de particular prosperidade (TORRES RODRIGUEZ, 1977, p. 220-221; 226; REINHART, 1952, p. 58; DÍAZ MARTÍNEZ, 1986-1987, p. 224), já que se encontrou à frente de uma instituição estável; governando um reino com fronteiras que se ampliavam; experimentando o aumento das suas bases, através de uma população cristã crescente, não poderia ser interpretado como indicação de que aquele quadro perpetuar-se-ia indefinidamente. As condições do Reino Suevo, durante o governo de Miro, não eram as mesmas desfrutadas por Teodomiro, as dificuldades começavam a surgir (DÍAZ MARTÍNEZ, 1986-1987, p. 224-225). A longevidade do mesmo estaria, pois, associada à capacidade do monarca em reconhecer os limites do sucesso alcançado no passado e estabelecer metas exequíiveis para o futuro.

Objetivando um melhor desempenho nas circunstâncias anteriormente identificadas, o monarca não deveria realizá-las de forma isolada ou solitária. Dessa maneira, como indica a frase posteriormente reproduzida, poderia usufruir de aconselhamentos.

Busca en tu ayuda consejos saludables (FVH, 2, XVI. p. 159).

Quem estaria capacitado a fornecer tais conselhos? Os eclesiásticos, conforme podemos observar nas citações e considerações destacadas a seguir.

(...) de vez en cuando da descanso a tu alma y llena este mismo descanso con estudios de sabiduría y con buenos pensamientos(...) (Idem, 2, XIII. p. 159) (o destaque é nosso). 
Sabemos que o acesso a atividades relacionadas ao estudo, em meados do século VI, só se viabilizava através da intermediação dos clérigos. Estes, particularmente na Galiza, puderam, com a fundação de Dume, importante centro de estudos (VELÁZQUEZ SORIANO, 1994, p. 334; GOMES, 1990, p. 158; FONTÁN, 1974/1979, p. 332), e outros mosteiros da mesma natureza, melhorar a sua formação intelectual. Dessa forma, concomitantemente à apresentação de indícios para a composição do modelo de monarca idealizado, ao ressaltar a importância dos "estudios de sabiduría", a construção martiniana nos indica igualmente a relevância do papel assumido pelos religiosos no reino, também ao sugerir ao monarca a busca do saber, só possível junto a estes. Provavelmente destinada a reafirmar esse papel, verificamos ainda outra curiosa referência:

Valoriza el consejo de los sabios(...) (FVH., 2, XIV. p. 159) (o destaque é nosso)

As três últimas citações revelam uma importante nuança da ação eclesiástica em relação ao paradigma de monarca que estava sendo formulado. Refiro-me ao fato de que os conselhos dos religiosos deveriam, sobretudo, preencher as lacunas decorrentes das dúvidas ou hesitações do governante. Em outras palavras, frente a dificuldades diversas, as orientações proferidas pelos clérigos teriam que, de acordo com o padrão real idealizado, ocupar espaço destacado junto ao monarca, já que estas estavam sendo apresentadas como uma manifestação da avaliação das maiores autoridades do reino.

Em linhas gerais, poderíamos, portanto, afirmar que, segundo a formulação presente na Formula Vitae Honestae, ao governante prudente cabia um comportamento que valorizasse determinados conselhos e

7 “(...) et requies ipsa plena sit sapientiae studiis.” (Idem. p. 149). que estivesse vinculado a uma vivência de acordo com a razão e voltado para a busca da verdade e não da dúvida; da essência e não da aparência; do duradouro e não do efêmero; do equilíbrio e não dos excessos.

\section{Justiça}

A justiça, assim como a prudência, também enfocada na Formula Vitae Honestae, possuiu um importante papel no conjunto de elementos que compõem o paradigma de monarca presente nas obras dedicadas ao rei suevo.

Martinho inaugurou as considerações desse conceito com uma indagação:

?Qué es la justicia sino un tácito concierto de la naturaleza descubierta para ayuda de muchos? (Idem, 5,I. p. 162) (o destaque é meu)

A idéia de justiça na obra martiniana expressa, crescente e paulatinamente, a presença de fundamentos pautados na consideração de um plano divino. Nesse sentido, o conceito adotado está inteiramente consoante à percepção que a Idade Média, que então se iniciava, teve da justiça. Como destaca Ernest Cassirer, os medievais jamais conceberam uma justiça impessoal e abstrata, nem puramente convencional. Nas palavras deste autor: O legislador tenía que estar por encima de toda la fuerza humana. La voluntad que manifiesta en la justicia es una voluntad sobrehumana (CASSIRER, 1992. p. 117).

Logo, apesar de Martinho ter associado a justiça, primeiramente, a "un tacito concierto de la nature$z a$ " ${ }^{8}$, toda a essência de sua conceituação remonta ao Sagrado. Vejamos a resposta que o próprio autor formulou à pergunta feita:

8 "Quid est autem Justitia, nisi naturae tacita conventio." (Idem. p. 155). 
Justicia no es constituición nuestra sino ley divina, vínculo de la sociedad humana (...) (FVH.,5,I. p. 162) (o destaque é nosso)

Embora a argumentação martiniana tenha se conduzido, como veremos adiante, no sentido de alertar ao rei Miro para a sua responsabilidade diante da prática da justiça, sua atenção privilegiou, inicialmente, o fornecimento de esclarecimentos quanto aos limites da participação real em tal processo. Ou seja, ao monarca havia que se demonstrar até onde poderia ir sua interferência em questões relacionadas à justiça. Esta, cuja origem e natureza já foram previamente definidas no plano divino, não poderia suscitar questionamentos. Vejamos:

\section{(...) te conviene cuanto ella (justiça) dictare (Idem, ibid)}

Dessa forma, comportar-se em conformidade com a justiça implicava necessariamente seguir determinados passos que corresponderiam ao agrado de Deus.

Todos por consiguiente, que deseáis praticarla [justiça), ante todo temed a Dios y amadlo, para que seáis amados por Dios (Idem, 5,II. p. 162) (o destaque é nosso)

Aqueles, portanto, que não reconhecessem o Deus cristão não poderiam ser justos, já que a justiça, associada à Verdade, como podemos observar na próxima citação, existia, segundo a argumentação martiniana, como pressuposto absoluto e irrestrito.

(...) en el supuesto de que Dios sea invocado en el juramento como El tambien es testigo para el que no lo invoca, no traspases la verdad, no sea que traspases también la ley de la justicia (Idem, 5,IV. p. 162) (o destaque é meu)

Considerando que o exercício da justiça não raramente exige a existência de uma autoridade capaz de julgar e punir, tal virtude assumia, no caso de um monarca cristão, uma conotação que empiricamente a diferenciava da manifestação da mesma virtude entre outros cristãos. Ser justo, no caso de um monar- ca, representava, entre outros aspectos, também a adoção de um tratamento semelhante para todos os que habitavam o reino. Assim, indicava-lhe a seguinte argumentação:

[Deves) favorecer a todos y no perjudicar a ninguno (FVH.,5,II. p. 162) (o destaque é meu).

Se à maioria da população atuar em consonância com a justiça implicava, em uma dada circunstância, por exemplo, respeitar e não prejudicar outras pessoas, ao monarca cabia algo mais. A este se impunha, pois, igualmente, uma atitude que coibisse a ação dos que agiam em prejuízo dos demais. A este respeito afirmou Martinho:

Para ser justo no sólo no harás daño, sino que estorbarás que lo hagan; porque el no hacer daño no es justicia, sino desinterés por lo ajeno. Empieza, pues por no robar, por subir a mayores cosas y por restituir lo quitado a los otros. Castiga y frena a los ladrones mismos para que no les teman los otros (Idem, 5,III. p. 162) (o destaque é meu).

A preocupação com a moderação na aplicação da justiça também não fora desprezada. Martinho aqui demonstrou interesse em indicar ao monarca que se pretendia moldar a indispensabilidade de uma conduta equilibrada. A esse respeito afirma:

(...) la justicia ha de ajustarse a la norma de que el respeto a su disciplina no se envilezca menospreciado por el excesivo descuido común, ni de que a causa de su atroz severidad habitual pierda la gracia de la amabilidad humana (FVH., 9,II. p. 163).

A Miro, mais do que um aconselhamento sobre como se conduzir, atribuía-se uma tarefa da qual dependia a plena manifestação da justiça no reino. Sendo a justiça "lei divina" (Idem, 5, I. p. 162), ao se orientar o monarca suevo no sentido de que ele se

\footnotetext{
9 “Justitia non nostra constituitio, sed Divina lex.”(Idem. ibid).
} 
tornasse um agente desta, a ele estava sendo conferido, igualmente, o status de instrumento da vontade de Deus.

Logo, nas observações sobre este elemento, tendo em consideração três dados que se inter-relacionam: a certeza de que em Deus se originava a justiça; que esta se impunha como uma verdade para todos os homens e que o monarca deveria atuar como agente da Sua vontade, indicava-se ao governante que se pretendia justo, ao qual a prática do Cristianismo se apresentava como uma necessidade, a possibilidade de dispor de um mecanismo de reforço às suas ações junto a todos os habitantes do reino.

No caso do Reino Suevo, sabemos que as populações eram, nesse momento, objeto de um amplo processo de cristianização e que as práticas pagãs possuíam inegável aceitação no noroeste peninsular, principalmente, entre as pessoas acomodadas no meio rural (MCKENNA, 1938. p. 75-107; FERREIRO, 1983; MACIEL, 1980). Estas, maioria no reino, não reconheciam, portanto, a autoridade do Deus cristão. Assim, ao expressar a legitimidade e a validade da justiça cristã mesmo para tais populações, Martinho conferia ao rei Miro um instrumento de atuação junto a todos os habitantes do reino, indiscriminadamente. Ou seja, oferecia-se ao monarca suevo, desde que, evidentemente, se pautasse no conjunto de orientações presentes nas obras a ele dirigidas, um importante artifício de reforço à legitimação da sua autoridade no plano ideológico.

Dessa forma, um comportamento em conformidade com a justiça, de acordo com o monarca idealizado nas obras dedicadas a Miro, em tese, concedia a Miro, simultaneamente, o respaldo Divino e, conseqüentemente, a possibilidade de usufruto de todos os benefícios de um governo tranqüilo. Em mais de uma circunstância, tais vantagens são claramente destacadas:

Si procuras, por tanto, consagrarte a la práctica de estas cosas, (menção à justiça) alegre y sereno esperarás el final de tu carrera, contemplarás con alegría las tristezas de este mundo, tranquilo las turbulencias, seguro las postrimerías (FVH., 5,VI. p. 162) (Sendo justo) Entonces todos te llamarán varón justo, te seguirán, venerarán y amarán (Idem, 5,II. p. 162).

A preocupação com a opinião que, de uma maneira geral, os habitantes do reino pudessem formular a respeito de Miro revela-se nesta última citação. Segundo a referida construção, buscou-se sublinhar o quão vantajoso um comportamento orientado pela justiça poderia representar. Nesse sentido, indagamos: Que juízo melhor poderia ser conseguido senão aquele capaz de suscitar um sentimento de veneração? Assim, a conduta justa traria como uma das suas recompensas a certeza de que todos "seguirán, venerarán y amarán" "10 o governante. Devemos ainda lembrar que tal certeza deveria ser valorizada, também, em função do interesse, já sublinhado nas abordagens da prudência, de que o monarca idealizado assumisse frente aos demais cristãos um exemplo a ser seguido.

Se a observação das duas citações anteriores nos remete à idéia de que uma conduta justa garantia a legitimação aos olhos de Deus e de todos os habitantes do reino, quais as consequiências previsíveis para o governo de Miro, caso o conjunto de orientações que lhe estava sendo oferecido fosse ignorado? Embora Martinho não tenha transformado tal problemática em uma formulação clara e objetiva, no enfoque da justiça, fazendo-o apenas no tratamento conferido à humildade, toda a sua construção, naturalmente, estivera pautada na possibilidade de que Miro pudesse fazer a si próprio a indagação anteriormente explicitada. Em outras palavras, não haveria sentido em se elaborar um padrão de monarca considerado adequado se as vantagens e, conseqüentemente, as desvantagens de uma conduta em consonância, ou não, com o referido conjunto não pudessem ser reveladas.

10 “(...) sequentur venerabuntur et diligent.” (Idem. ibid). 
Conforme a argumentação presente na Formula Vitae Honestae, poderíamos, portanto, afirmar que o monarca justo deveria atuar como agente da justiça divina, seu promotor em potencial aos olhos dos habitantes do reino, o que se relacionava naturalmente com a prática da religião cristã e com a consideração das orientações conferidas pelos clérigos. Nesse sentido, de acordo com a definição de justiça, presente no modelo de monarca elaborado no Reino Suevo, sugeria-se uma conduta que buscasse garantir a aplicação, a manifestação e manutenção da justiça no reino.

\section{Humildade}

A humildade, objeto central da obra Exhortatio Humilitatis, assim como a prudência e a justiça, estas enfocadas na Formula Vitae Honestae, como já destacamos, encontra-se no paradigma de monarca presente nas obras dedicadas ao rei Miro como um dos principais traços a compor o perfil do monarca desejado. Diferentemente, contudo, da prudência e da justiça, a humildade não faz parte do conjunto de virtudes denominadas cardeais. A íntima relação, portanto, verificada entre estas e um plano designado como filosófico-moral, não corresponde à natureza da virtude da humildade. Desse modo, poderemos observar, como uma das mais marcantes características no tratamento que lhe foi dado, o fato de que esteve explícita e permanentemente identificada com os preceitos cristãos. Logo, ao enfocar a humildade, Martinho não evocou valores de ordem moral como se fossem independentes à fé, como fizera na abordagem da prudência. Quando sublinhou tais valores, fêlo evidenciando sua inserção no âmbito do cristianismo.

Assim, desde o início da abordagem, o Bracarense procurou destacar a presença e importância do Divino, caracterizando a Exhortatio Humilitatis, como um escrito de cunho eminentemente cristão.
Nesse sentido, os conselhos fornecidos a Miro, claramente revelaram que o monarca idealizado não se poderia forjar fora de um ambiente cristão.

Conduzir-se com humildade, segundo as preocupações presentes no enfoque dessa virtude, entre outras iniciativas, significava a adoção de uma postura que valorizasse a verdade. Não uma verdade subjetiva, ou seja, do próprio monarca ou de Martinho, mas sim aquela considerada única, visto que de procedência divina. Isto é, a verdade apresentada por Martinho, em seu papel de intérprete e porta-voz de Deus. Desse modo argumentou a respeito:

Y si parece tal vez que hablo con alguna dureza, la culpa es de la verdad y no mia (...) aunque en algunas ocasiones se le (a Miro) ofrezca, como suele acontecer, como desagradable, has de beberla como antídoto, aunque sea fuerte y amargue, porque es saludable (EH., II. p. 87) (o destaque é meu).

Impunha-se, pois, como característica do monarca que se desejava moldar, a busca da verdade que, assim como a justiça, concebia-se procedente diretamente de Deus. Em outra ocasião, mais uma vez, de forma explícita, a ela se fez referência:

(...) grande y detestable falta ante los ojos de Dios consiste en tener una cosa en el corazón y manifestar otra con la boca (EH., IV. p. 88).

É a partir da consideração de que a ausência da verdade se constituía como grave falta, que as críticas aos aduladores que eventualmente cercavam o monarca foram feitas. A preocupação com a atuação dos bajuladores presentes na corte manifestou-se pujantemente nos comentários sobre a humildade na Exhortatio Humilitatis. Vejamos a primeira advertência sobre tal situação existente na obra:

Ante todo te exhorto a que profeses un temor constante a los halagos exageradamente lisonjeros de los hombres (Idem, III. p. 87). 
Indicou-se ao monarca considerável cautela no trato com os que excessivamente elogiavam suas atitudes, entre outros aspectos, com a alegação de que tais homens poderiam se afastar, indefinidamente, da verdade, apenas tendo como critério para a sua atuação os próprios interesses. Nesse sentido, Martinho a eles se reportou:

(seu) oficio proprio consiste en seguir principalmente las palabras de los poderosos y en hacer frases según el antojo de aquéllos; porque si casualmente alaban algo y ven que no les escuchan de buen grado, inmediatamente se convierten en acusadores de lo que antes alababan (Idem, V, p. 87).

Logo, alertava-se o monarca do perigo em que consistia confiar nas palavras dos aduladores, já que estas se flexibilizavam a partir de critérios inescrupulosos. Este encaminhamento eliminava a possibilidade de poder contabilizar os homens que assim se comportavam como verdadeiros colaboradores. Considerando a importância entre os cristãos de uma vida em conformidade com a verdade, podemos admitir que, ao menos em teoria, não havia eclesiásticos aduladores à volta de Miro. Se identificarmos tais aduladores como mentirosos e, concomitantemente, designarmos sua procedência fora do círculo religioso, a estratégia de conceder aos eclesiásticos um destacado papel de interferência junto ao monarca, presente nas entrelinhas das obras dedicadas ao monarca, como já pudemos verificar no enfoque da prudência, afirmava-se. Ainda nesse sentido as duas citações, abaixo destacadas, lembram a necessidade de se valorizar as palavras proferidas pelos religiosos em detrimento das formuladas pelos aduladores:

El profeta David afirmó que era mejor para él ser repreendido o amonestado por un hombre justo que ser ensalzado por un adulador cualquiera (Idem, III. p. 88). Así pues, dispensa mejor acogida a las palabras útiles que a las de condescendencia, atiende más a las rectas que a las afables y a las complacencias (Idem, IV. p. 87)
Insistindo na idéia de valorização do papel dos eclesiásticos junto a Miro e considerando a importância de um comportamento que diferenciasse o monarca que se pretendia moldar dos demais governantes, já que a estes, em geral, as palavras de elogios agradavam, Martinho destacou, em tom de reprovação, a atitude de tais reis:

Es defecto de reyes tener complacencia con los aduladores, lo mismo que es servil el adular (Idem, ibid).

Dessa forma, verificamos que o tratamento dado a esta questão procurou caracterizar a prática da mentira como um mecanismo fomentador do abandono da humildade. Ou seja, ao valorizar os elogios enganosos provenientes dos aduladores, o monarca estaria mais exposto à possibilidade de desconsiderar a necessidade de ser humilde, esquecendo que todos os elogios, agradecimentos e glórias deveriam ser tributados a Deus. Vejamos uma das várias vezes (Idem, III, p. 87; IV; 8, IV. p. 90) em que Martinho se pronunciou sobre esta questão:

(...) cuando numerosos aduladores de una y otra parte no te insinúen sino lo que saben que te halaga, ofreciéndote ciertas frases de glorificación, en las cuales se te dice lo que a Dios, comprendes que de ellas no hay nada propio tuyo (...) (Idem, I. p. 88).

Tendo em Deus o centro em torno do qual são tecidos os comentários sobre a humildade, a Ele se associaram outras considerações, concebidas não como virtudes a serem incorporadas pelo monarca idealizado, mas como pressupostos nos quais a conduta deste dever-se-ia pautar e jamais desprezar. Entre tais pressupostos sublinhamos três.

Como primeiro aspecto, poderíamos lembrar que cabia ao monarca, como servo de Deus, comportarse como um instrumento da Sua vontade. Aqui, utilizando-se de uma passagem das Sagradas Escrituras, 
Martinho reforçou tal pressuposto, já esboçado na abordagem da justiça:

Deseo con afinco que observes todos los mandamientos de Cristo (..)"Y cuando hubiereis hecho (diz-lhe o Senhor) todas estas cosas que os mando, decid: Siervos inútiles, fuimos; hicimos lo que debimos hacer" (Lc 17,10), o sea, por deuda, como siervos (EH., V. p. 89).

Como servo de Deus, o monarca deveria, na sua ação de governar, portanto, também expressar tal subordinação. Assim, o sucesso de seu governo estava associado à sua capacidade de ser humilde.

(...) la verdadera y cristiana humildad. Con ella gobernarás excelentemente a aquellos que tienes a tu cargo (Idem, I. p. 90) (o destaque é meu).

Considerando as circunstâncias que o Reino Suevo atravessou durante o reinado de Miro, visto que, após um período de prosperidade referente ao governo de Teodomiro, as dificuldades começaram a se apresentar e a colocar em risco a integridade do reino (DÍAZ MARTÍNEZ, 1986-1987, p. 224-225), a idéia de governar excelentemente ${ }^{11}$ não poderia, também, desconsiderar a intenção de que o monarca suevo fosse capaz de promover, e estender a todas as populações do reino, segurança, sobretudo frente ao inimigo mais imediato, os visigodos. Mas, Martinho não se reportava apenas às consequiências materiais de tal encaminhamento, segundo seu raciocínio, cabia também ao monarca garantir às populações a ele subordinadas todos os benefícios de um governo pautado nos princípios cristãos. Vejamos um exemplo de como se expressou a respeito:

(...) a fin de que aventajes a los demás en la utilidad de un buen gobierno, te suplico acojas con cariño esta insignificante

11 “In hac eos, quibus praesides, optime gubernabis." (Idem. p. 201). exhortación mía (refere-se a obra como um todo) (EH., I. p. 87) (o destaque é meu).

Compreendendo que tais benefícios estariam diretamente associados a uma crescente aceitação do Cristianismo no reino, com o que se vinculava uma maior atuação da Igreja, há que se ressaltar que qualquer atitude do monarca que visasse a ampliação da esfera de ação desta instituição estaria, conforme o raciocínio martiniano, condizente com a sua obrigação em dar uma maior utilidad ${ }^{12}$ ao seu governo.

O segundo pressuposto, subjacente a toda a argumentação realizada na construção de um paradigma de monarca, concerne à indicação de que se existiam recompensas em decorrência de um comportamento apropriado, existiam também punições para uma conduta desvirtuosa.

(Se) a Dios le tributamos alabanza con los labios, a nosotros con los labios y con el corazón. Esta es la razón por la cual la mayor parte de las veces se levanta de nuevo el enemigo postrado, porque en el pecado de nuestra soberbia radica su fortaleza (EH., III. p. 90).

O terceiro desses pressupostos diz respeito à concepção, reconhecida e anexada por Martinho, de que o poder dos governantes procedia de Deus, o que remetia o monarca idealizado à categoria de devedor.

Tú, quienquiera que por voluntad de Dios brillas en la dignidad de algún cargo(...) (EH., I. p. 87) (o destaque é meu).

Um monarca de origem germana, a principio, não poderia reconhecer a origem do seu poder em outro plano que não o mesmo que sustentou seus antepassados. A Monarquia Sueva se encontrava pautada particularmente no prestígio de uma reconhecida liderança militar e no critério hereditário como definidor do

\footnotetext{
12 “(...) hic providae gubernationis utilitate ceteris praecedis hominibus (...)"(Idem. p. 195-196).
} 
processo sucessório, forma essa capaz de garantir que uma determinada família, considerada especial, mantivesse-se no poder. A indispensabilidade da ratificação da assembléia de guerreiros ou de um Conselho de nobres assumia em tal conjuntura papel de destaque.

Considerando que a prática da humildade cristã não se poderia concretizar sem o reconhecimento de uma dívida para com o Divino, bem como sem a neutralização de alguns aspectos da herança germana de Miro - como a importância atribuída aos Conselhos e aos antigos critérios de legitimação da Monarquia - compreende-se a insistência com que Martinho abordou a questão. Em outras palavras, por um lado, sendo a humildade fundamental ao perfil do monarca idealizado, já que definia, como nenhuma outra virtude anteriormente abordada, a essência deste como predominantemente cristã e, por outro, reconhecendo a possibilidade de arraigamento da tradição germânica, referente à sucessão, junto a Miro, não nos surpreende a verificação de que o bispo bracarense tivesse explicitado tal concepção em três momentos específicos: na primeira linha da obra Exhortatio Humilitatis, como observamos na última citação; no que corresponde aproximadamente à metade da obra e nas suas últimas sentenças, como indicam as duas próximas referências. Nestas, inclusive, utilizou-se, como podemos observar, de menções às Sagradas Escrituras.

“Quién, pues, tiene algo que no se le haya dado?"(Cor 4, 7) (EH., VI. p. 89) (o destaque é meu). "Qué tienes que no recibiste? $S i$, pues lo recibiste, por qué te glorías como si no lo hubieras recibido?" (I Cor 4, 7) E igualmente otro del Apóstol: "Todo don excelente y todo don perfecto es de lo alto proveniente del Padre de las luces” (Tg 1, 17) ( EH., VIII. p. 90-91) (o destaque é meu).

De acordo com os princípios destacados no enfoque da humildade, realizada na Exhortatio Humilitatis, poderíamos, portanto, afirmar que o monarca humilde deveria, sobretudo, considerar as potencialidades do poder Divino e a sua subordinação a Ele. Nesse sentido, teria que se comprometer com a Verdade; reconhecer a Sua autoria em todas as ações que fossem objetos de elogios, agradecimentos e glórias; apresentar-se-lhe como possuidor de uma dívida irresgatável e atribuir-Lhe a origem de todo e qualquer poder. Assim, de acordo com a definição de humildade, presente no modelo de monarca elaborado no Reino Suevo, sugeria-se ao monarca uma conduta que aplicasse as orientações fornecidas pelos clérigos e que buscasse um comportamento plenamente compatível com os pressupostos e valores cristãos.

Concomitantemente à abordagem e valorização da prudência, da justiça e da humildade, sublinhadas por Martinho Braga na elaboração de um modelo de monarca, alguns pressupostos foram apresentados e receberam semelhante importância na formulação do referido paradigma. Assim, embora enfocadas por Martinho em obras diferentes, a nossa eleição pela análise desses três elementos se justifica não apenas pela sua própria relevância, mas também pela possibilidade de nos revelar a lógica da construção martiniana e os mais destacados dos pressupostos anteriormente mencionados.

Tendo em vista que o processo de cristianização empreendido no reino suevo possuiu variadas nuanças e que a redação de obras ao monarca se inseriu em tal conjuntura, igualmente podemos considerar que a cristianização implicou no lento e crescente processo de substituição e/ou subordinação dos valores germânicos aos princípios morais do Cristianismo. Assim, no que se refere ao monarca, observamos que a Formula Vitae Honestae corresponderia a uma fase inicial desse processo, enquanto a Exhortatio Humilitatis estaria identificada com uma etapa mais avançada do mesmo.

De uma maneira geral, contudo, Martinho, na forma como estruturou seus comentários, conduziu-se segundo uma orientação básica. Ele não só dissertou sobre atitudes adequadas, mas igualmente procurou aconselhar o monarca, indicando uma clara concep- 
ção moral da Monarquia. Paulatinamente, portanto, a esta concepção, vinculou-se a idéia de que um comportamento adequado do rei suevo, possível apenas no âmbito do Cristianismo, garantiria a legitimação aos olhos de Deus e de todos os habitantes do reino. Buscou-se, também, destacar a procedência divina do poder de Miro e o conseqüente status de instrumento de Deus conferido a este monarca,

\section{Bibliografia:}

Fontes Primárias:

A Bíblia de Jerusalém. 5a imp. São Paulo, Paulinas, 1991.

FORTUNATUS, V. "Opera Omnia”, In: Patrologiae. Cursus Completus. Serie Latina. ed. J. P. Migne. Paris, Garnier, 1862. v. 88 . Lib. $5,1$.

GRÉGOIRE DE TOURS. Histoire des Francs. Traduite du latin par Robert Latouche. Paris, Les Belles Lettres, 1996. 2 t. T.1.

HYDACE. Chronique. Introduction, texte critique, traduction par Alain Tranoy. Paris, Cerf, 1974. 2 v. v.1 (Sources Chrétiennes, 218).

ISIDORO DE SEVILLA. Historia de los Godos, Vándalos y Suevos. Estudio, edición crítica y traducción de Cristobal Rodriguez Alonso. León, Caja de Ahorros y Monte de Piedad de León y El Archivo Histórico Diocesano de León, 1975.

MARTIN DE BRAGA. Obras Completas. Versión castellana, edición y notas por Ursicino Dominguez del Val. Madrid, Fundación Universitaria Española, 1990.

. “Apendice III”, In: FLOREZ, Henrique. España Sagrada. Theatro Geográfico-Histórico de las Iglesias de España. Madrid, Fortanet, 1906. 52 v. v.15.

MARTINHO DE BRAGA. Vida e Opúsculos de S. Martinho Bracarense. Edição de Antonio Caetano Amaral. Lisboa, Academia Real das Sciencias, 1803.

MARTINI EPISCOPI BRACARENSIS. Opera Omnia. Edidit Claude W. Barlow. New Haven, The American Academy in Rome, 1950.

PASCHASIUS. "Vitae Patrum", In: Patrologiae. Cursus Completus. Series Latina. ed. J. P. Migne sucessores. Paris, Garnier, 1879. v. 73. bem como o quão importante deveria se constituir o seu papel enquanto exemplo de conduta para os habitantes do reino. Objetivou-se, ainda, particularmente, ressaltar que a indicação dos parâmetros de tal conduta cabia aos eclesiásticos, intérpretes das palavras divinas, valorizados especialmente como conselheiros, únicos capazes de apresentar um padrão de comportamento tido como ideal para um monarca cristão.

Fontes Secundárias:

BARbosA, A. de Miranda. "O Senequismo dos Opúsculos Morais de São Martinho", Bracara Augusta, Braga, v. 5, 1954, p. 259-271.

. "O senequismo medieval e o corpus martinianum". Biblos, v. 41, p. 181-191, 1965.

BARNES, J. et al. Les stö̈ciens et leur logique. Actas du Colloque de Chantilly. Paris, Vrin, 1978.

BRUN, Jean. O Estoicismo. Lisboa, Edições 70, 1986.

CASSIRER, Ernst. El Mito del Estado. 2. ed. 7. reimp. México, Fondo de Cultura Económica, 1992.

DÍAZ MARTíNEZ, Pablo C. "La Monarquia Sueva en el s. V. Aspectos Políticos y Prosopográficos”, In: Studia Historica. Historia Antigua. Salamanca, v. 4/5, n. 1, 1986-1987, p. $205-$ 226.

FERREIRO, Alberto.'The Missionary Labors of St. Martin of Braga in 6th Century Galicia", In: Studia Monastica, Barcelona, v. 23, n. 1, 1981, p. 11-26.

. "St. Martin of Braga's Policy toward Heretics and Pagans Practices", The American Benedictine Review, New York, v. 34, 1983, p. 372-395.

FONTÁN, Antonio. "Martín de Braga, un Testigo de la Tradición Clásica y Cristiana", Anuario de Estudios Medievales, Barcelona, v. 9, 1974/1979, p. 331-341.

. La Tradición de las Obras Morales de Martin de Braga", Boletin de la Universidad de Granada, Granada, n. 23, 1951, p. 73-86.

GOMES, Manuel Jorge da Silva. "S. Martinho de Dume: a sua 
ação litúrgico-pastoral”, Actas do Congresso Internacional do IX Centenário de Dedicação da Sé de Braga. Braga, 1990. v. 3. p. $157-166$.

GRIERSON. P. "Election and Inheritance in Early Germanic Kingship”, In: The Cambridge Historical Journal, Cambridge, v. 7, n. 1, 1941, p. 1-22.

GRIMAL, Pierre. Sénèque. Paris: Fayard, 1991.

ISLA FREZ, Amancio. "Las relaciones entre el reino visigodo y los reyes merovingios a finales del siglo VI", España Medieval, Madrid, n. 13, 1990, p. 11-32.

JULLIARD, Jacques. "A Política". In: LE GOFF, Jacques e NORA, Pierre.(dir.), História: Novas Abordagens. Rio de Janeiro, Francisco Alves, 1976, p. 180-196.

LE GOFF, Jacques. "A Política será ainda a ossatura da história?", In: O Maravilhoso e o Quotidiano no Ocidente Medieval. Lisboa, Edições 70, 1985, p. 221-242.

LIEFOOGHE, A. "Les Idées morales de Saint Martin de Braga", Mélanges de Science Religieuse, Lille, n. 11, 1954, p. 133146.

LOPES, Francisco Fernandes. "Comentário à Formula Vitae Honestae". Bracara Augusta, Braga, v.8,1957, p. 314-327.

MACIEL, Manuel Justino Pinheiro. "O De Correctione Rusticorum”, Bracara Augusta, Braga, v. 34, 1980, p. $485-$ 561.

MOUSNIER, R. "Las Realezas de Origen Germánico", In: La Monarquia Absoluta en Europa. Del siglo V a nuestros dias. Madrid, Taurus, 1986. p. 15-27.

PRIETO PRIETO, A. "El Marco Político Religioso de los Concilios Bracarenses I y II". In: $O$ Concílio de Braga e a Função da Legislação Particular da Igreja. Atas da XIV Semana Internacional de Direito Canônico, Braga, 1975. p. 33-91.

REINHART, Wilhelm. Historia General del Reino Hispánico de los Suevos. Madrid, Publicaciones del Seminario de Historia Primitiva del Hombre, 1952.

SOARES, Torquato de Sousa. "Estado Social e Político do Noroeste da península no século VI", Bracara Augusta, Braga, v. 8, 1957, p. 378-383.

SOUSA, Manuel Ferreira. "A Filosofia Moral de S. Martinho de Dume, em Antologias Senequistas", Revista Portuguesa de Filosofia, v. 36, 1980, p. 20-49.

TAVARES, Severiano. "O Senequismo de S. Martinho de Dume”, Revista Portuguesa de Filosofia, v. 6, 1950, p. 381387.

THOMPSON, E. A. Los Godos en España. Madrid, Alianza, 1971.

"The Conversion of the Spanish Suevi to Catholicism", In: Visigothic Spain: New Aproaches. Oxford, Clarendon, 1980. p. 77-92.

TORRES LOPEZ. Manuel. "Las Invasiones y los Reinos Germánicos de España”, In: MENENDEZ PIDAL, R (dir.) Historia de España. España Visigoda, v. 3. 2. ed. Madrid, Espasa-Calpe, 1963, p. 3-140.

TORRES RODRIGUEZ, Casimiro. "Reintegración de los suevos en la Iglesia Católica. S. Martin de Braga", Boletin de la Universidad Compostelana, Santiago de Compostela, n. 66, 1958, p. 11-30.

El Reino de los Suevos. La Coruña, Fundación "Pedro Barrie de la Maza Conde Fenosa", Instituto "P. Sarmiento" de Estudios Gallegos, 1977.

VELÁZQUEZ SORIANO, Isabel. "Ambitos y ambientes de la cultura escrita en Hispania (s. VI): De Martín de Braga a Leandro de Sevilla", Studia Ephemeridis Augustinianum, Roma, n. 46, 1994, p. 329-351.

VELOZO, Francisco José. "O Direito sucessório da Monarquia suévico-lusitana”, Scientia Juridica, Braga, 1951, p. 198-208.

Endereço da Autora: UFRJ • Instituto de Filosofia e Ciências Sociais • Dept ${ }^{\circ}$ de História • Largo de São Francisco, n $01 ・$ CEP 20051 070 • Centro • Rio de Janeiro • Brasil 